\title{
Oktay Rifat'ın Yağmur Sıkıntısı ve Auguste Strindberg'in Matmazel Julie Adlı Oyunlarını Birlikte Okumak
}

\author{
Reading Rifat's Yağmur Sıkıntısı with Strindberg's Miss Julie \\ M. Elif Tüfekçi*
}

\section{ÖZET}

Yağmur Sıkıntısı ve Matmazel Julie oyunlar birlikte okunduğunda, toplumsal alanda yaşanan değer değişiminin, birey üzerindeki etkisi gibi ortak izlekler dışında, aksiyonun ve karakterlerin gelişiminde, zaman ve mekanın kullanılışında belirgin paralelliklerin izini sürmek mümkündür. Makalede, Oktay Rifat ve Auguste Strindberg'in aynı izlek üzerine kurdukları oyunlarını işleyiş biçimlerindeki parallelikler ve farklılıklar üzerinde durulmuştur.

\begin{abstract}
Yăgmur Sıkıntısı and Miss Julie are interpreted together, in order to find certain similitaries in the development of action and characters, and the use of time and space can be observed along with the common themes like the effect of changes in the values of the society upon the individual. This article examines the similarities and differences in the way Oktay Rifat and Auguste Strindberg costruct their plays which are built upon the same theme.
\end{abstract}

Oktay Rifat'ın Yağmur Sıkıntısı ve Auguste Strindberg'in Matmazel Julie oyunları iki perdeden oluşan, tek mekanda geçen, oyun süresi ile oyunun öyküsünün süresi eş olan, temel oyun kişisi sayısının iki olduğu oyunlardır. Yağmur Sıkıntısı oyunu karı-koca olan İnci ve Arif'in aralarındaki diyaloglarla sabah saatlerinde modern bir apartman dairesinin mutfağında geçer. Bir emlak komisyoncusu olan Arif ve ev kadını olan karısı İnci'nin kahvaltı masasında ufak çekişmelerle başlayan tartışmaları kıyıcı bir savaşa dönüşecek, aynı evin içinde karı-koca olarak yaşayan bu iki insanın üzerinden yazar toplumsal bir bakış açısı geliştirecektir. Çayın konulmamış olmasıyla başlayan tartışma giderek derinleşecek, İnci'nin bir başka adamı sevdiğini açıklamasıyla doruğa çıkacaktır. Oyunun ikinci bölümünde bunalımı iyiden iyiye artan İnci, kocasının telkiniyle uyku ilacı alarak yaşamına son verecektir. Matmazel Julie oyununda ise Kont'un kızı Julie ile uşak Jean'ın arasında yaşanan beraberlik üzerinden cinsel ve sınıfsal savaşım örneklenir. Fırsatçılığ 1 ve yükselme hırsıyla öne çıkan Jean, yaşadıkları beraberliği kullanarak sınıf atlamak isteyecek, başaramadığı noktada Julie’yi intihara sürükleyecektir.

\footnotetext{
* Araştırma Görevlisi, Ankara Üniversitesi, D.T.C.F. Tiyatro Bölümü
} 
Yağmur Sıkıntısı ve Matmazel Julie oyunlarının ortak izleklerinden birini değer değişimi oluşturur. Her iki oyunda da toplumsal alanda görülen ekonomik, sosyal, kültürel ve bilimsel gelişmelerin ve bu gelişmelerin yarattığ değer değişiminin izi sürülebilir. Matmazel Julie oyununda uşak Jean karakteriyle somutlanan değer değişimi, dönemin ekonomik ve toplumsal yapısının yansımasıdır. Liberalizm, Milliyetçilik ve Endüstri Devrimi, 18. yüzyılın sonlarına kadar üretim kaynağı olan toprağı ellerinde bulundurdukları için siyasal gücün de sahibi olan toprak aristokrasisinin elinden bu gücü alır. Endüstri Devrimi ile birlikte değișen ekonomik yapı, yeni buluşlar, buhar gücü ile çalışan makineler sermaye birikimini artırır. Ekonomik alanda yaşanan bu köklü değişiklikler toplumsal alanı derinden etkiler. Büyüyen sermaye rekabeti körükler, para ve çıkar kaygısı ahlaki değerleri alt üst eder. Böyle bir dönemin oyun kişisi olan Jean "sınıf atlamak" uğruna önüne çıkan her engeli, ne şekilde olursa olsun aşmaya kararlıdır:

Gördüğüm düşte, hep karanlık bir ormanda, büyük bir ağacın altında yatıyorumdur. Yukarılara çıkmak isterim, ağacın ta tepesine kadar çıkıp, güneşin aydınlattığı, 1şıltılı görünüme oradan bakmak, sonra o tepede duran yuvadaki altın yumurtaları almak. Ha bire tırmanırım, ağacın gövdesiyse kalın ve kaygandır, daha ilk dala bile ulaşamam. Ama bir kez ulaşınca, sanki merdivenden çıkar gibi ağacın tepesine kolayca varacağımı bilirim. Şimdilik o dala ulaşamadım, ama yakında ulaşacağım, düşlerimde bile olsa ${ }^{l}$

Matmazel Julie oyununda, çağın bilim ve düşünce alanındaki değişimleri de belirgin bir biçimde gözlemlenebilir. Sigmund Freud'un bulguları, Charles Darwin'in kuramları, Hippolyte Taine'in “1rk, ortam, zaman" kuramı, Seneca Falls Bildirisi verilebilecek ilk örneklerdir.

Oktay Rifat, Yağmur Stkıntısı'nda toplumdaki değer karmaşasını Strindberg'in Matmazel Julie'sinde yaptığı gibi oyunun erkek karakteri üzerinden işler. Arif de tıpkı Jean gibi toplumsal, ekonomik ve kültürel alanda yaşanan değişikliklerin gereğine kendi çıkarları doğrultusunda ayak uydurmak konusunda kararlıdır. Matmazel Julie oyununda izi sürülen değişim gibi, Yağmur Sıkıntısı oyununda dönemin Türkiye'sinin içinde bulunduğu ekonomik yapı ve toplumsal değer değişimi serimlenir. Cumhuriyet'in ilk yıllarından beri siyasal iktidarı elinde bulunduran asker-sivil-bürokrat kadrolar, İkinci Dünya Savaşı sonlarında totaliter rejimlerin yıkılışı ve demokrasi kültürünün üstün gelmesi sonucu yoğun bir muhalefetle karşılaşır. Yükselen muhalefet içinde ticaret ve maliye burjuvazisinin yanı sıra, esnaf ve toprak ağaları, savaş sırasında yaşanan sıkıntılar, yapılamamış toprak reformu gibi sebeplerle de küçük memur, işçi ve köylüyü kapsayan geniş halk yığınları yer alır. Böyle bir ortamda ticaret ve maliye burjuvazisinin sözcüsü olarak doğan Demokrat Parti, 1950 yılında iktidara gelir. Tek parti döneminden çok partili siyasal yaşama geçen Türkiye ekonomisi 1950-1960 
yılları arasında dışa bağımlı bir kapitalizme de geçiş yapar. Ülke ekonomisi dışa bağımlı bir özellik göstermekle kalmayacak "kapitalizm öncesi ilişkileri de barındıran, emperyalizme bağımlı bir biçimde kapitalistleşen bir üretim biçimine sahip olacaktır."2 Ekonomik alanda yaşanan bu köklü değişim, toplumsal hayatın her alanına etki eden bir değer farklılaşmasına yol açar. Bu, toplumsal hayatın her alanına sinmeye başlayan firsatçılık, açıkgözlülük, kısa yoldan haksız kazanç elde etme gibi orta sınıfa egemen olmaya başlayan bir değer sistemidir:

Arif: Biz kendi yağıyla kavrulan, ayağını yorganına göre uzatan sümsük kişilerden değiliz. Bizim ufak tefek hesaplar umurumuzda değil. Geçti o bir lokma, bir hırka çağları. Bizim gözümüz zenginlikte. Kalkınmak istiyoruz. Bugün koskoca devletler bile veresiye yaşıyor. Bak Türkiye'ye, gırtlağına kadar borç! Borç veriyorlar ki borcu var. ${ }^{3}$

Her iki oyunda da, toplumun yerleşen yeni değerlerine ayak uyduran, güçlü olan ayakta kalacak, tutunamayan ise yaşamını sonlandırmaktan başka bir çıkış bulamayacaktır. Oyunların erkek kahramanlarında somutlanan "sınıf atlama" isteği ve bu isteğe ulaşma doğrultusunda izlenen yol, değişen toplumsal değerlerin en belirgin göstergesidir. Yağmur Sıkıntısı'nın Arif'i, varolan çarpıklığa kendince uyum sağlamış bir oyun kişisi olarak çizilmiştir. Bu uyum, kurnazlığı, fırsatçıllı̆̆, hileciliği, haksız kazanç elde etmeyi, rüşvet vermeyi, iş bitiriciliği içinde barındırır. Dönemin Türkiye'sine hakim olan, sağlam temellere dayanmayan, altı boş ekonomik sistem bu tip davranışlarla kısa yoldan zengin olmayı olumsuzlamamaktadır. Arif' in gazeteden yüksek sesle okuduğu haberlerle, varolan çarpıklıklar onun ağzından seyirciye iletilir. Arif tüm bu haberlere, kurulmakta olan düzene uyum sağlamış bir adamın tepkileriyle karşılık verecektir:

Arif (gazetesini okur): Besin maddelerinin yüzde yetmiş beși bozuk ve hileli. Vay anasına! ${ }^{4}$

Arif: Ankara'nın dumanlı havasında neler dönüyor?.. İki yüz milyon liranın hesabı nerede?... İyi para! ${ }^{5}$

Arif: Türk iş̧̧ileri dolandırıldı. (Güler) Türk gibi güçlü... Hey gidi aslanlar!..6

Arif ve çevresinin temsil ettiği ve yavaş yavaş orta sınıfa hakim olan anlayış tüm ahlaki değerleri çöküntüye uğratan yeni bir yaşam biçimi tarif etmeye başlamıştır. Böyle bir düzende ayakta kalabilmek için ahlaki değerler, yasaklar, vicdan muhasebeleri bertaraf edilmelidir. Arif de vicdanıyla ekonomik çıkarlarını çarpıştırdığında galip gelen çıkarları olur. Bu çarpışma Arif'e kendiyle çelişmemeyi, tutarlı olmayı öğretmiştir. Bu sebeple oyun boyunca gözler önüne serilecek olan ahlaki çöküntüsü onu rahatsız etmeyecek, uyum sağlamanın gücüyle tutarlı davranışlar sergileyecektir. Arif

\footnotetext{
${ }^{1}$ August, Strindberg. Strindberg Seçilmiş Oyunlar 1. Çev.: Aziz Çalışlar, Turan Oflazoğlu, Afif Obay. (İstanbul: Adam Yayınları, 1982),s., 107.

${ }^{2}$ Server Tanilli, Uygarlık Tarihi. (İstanbul: Cem Yayınevi, 1992), s., 341.

${ }^{3}$ Oktay Rifat, Toplu Oyunları. (İstanbul: Adam Yayınları,1988), s., 271-272.

${ }^{4}$ O.Rifat, A.g.e. s., 269.

${ }^{5}$ A.g.e. s., 269.

${ }^{6}$ A.g.e. S., 270.
} 
düzenle bağını korurken kendi içinde bir mahkeme yapmış ve çıkarından yana olanla uzlaşmıştır. $\mathrm{Bu}$ uzlaşma kendini ironik bir biçimde gösterir. Şöyle ki, Shakespeare'in Hamlet oyununda Marcellus'a söylettiği ünlü replik "Çürümüş bir şey var Danimarka krallığında", Oktay Rifat tarafından Arif’e söyletilir. Hamlet oyununun bu ünlü repliği, ülkenin içinde bulunduğu durumdan sıkıntı duyan bir taraf ağzından dillendirilir. Marcellus, çürümüşlükten doğan rahatsızlı̆̆ imler. Oysa Arif çürümüşlükten çıkar sağlayan, bu durumdan rahatsız olmak bir yana çürümüşlüğe hizmet eden, hizmetinin karşılığını da maddi kazançla perçinleyen taraftadır. Arif' in çürümüşlükten bu denli rahat ve alaycı söz etmesi, onun gelişimini tamamlamış olmasını ve rahatlığını kanıtlar niteliktedir. Çürümüşlükten söz edenin çürüyenin ta kendisi olması ironiktir.

Matmazel Julie oyununun Jean karakterine bakıldığında Arif karakteriyle benzer özellikler taşıdığı göze çarpar. "Fırsatları değerlendirmek”, "yukarı tırmanmak”, “dala ulaşmak”, "altın yumurtaları toplamak", Julie ile yaşadığı ilişkiyi kullanmak isteyen Jean'ın hedefinin parçalarıdır. Birlikte oldukları gecenin sonunda Kont dönmeden önce soğukkanlılıkla oturup geleceklerini kararlaştırmak istediğini söyleyen Jean, aslında Julie'yi kendi düşünceleri doğrultusunda yönlendirmek ister. Hayallerini gerçekleştirmek için öncelikle sermayeye gereksinimi vardır; ancak Julie'nin kendi adına hiç parası yoktur. Bu noktada aralarında kıyıcı bir savaş başlar. Bu savaş Darwin'in “doğal eleme kuramı”nda olduğu gibi güçlü olanın ayakta kaldığı, güçsüz olanın yenik düştüğü bir savaş olur. Yağmur Sıkıntısı'nın İnci'si gibi, Matmazel Julie'nin Julie'si de değişen değerlere ayak uyduramadıkları sürece kaybetmeye mahkumdur.

Oyunun hemen başında uşak giysileri içinde gördüğümüz Jean'ın, üst sınıfa gönderme yapan ilk seçiciliği yemeğe aittir. En sevdiği yemek olan “böbrek”i yemek için Kristin'den tabağ 1sıtmasını istemesinde kendi sınıfına ait olmayan bir tavır gözlemlenmektedir. Çünkü Jean daha sonra bira içmek yerine eliyle 1sıttığı şarabı “balon bardakta” içmeyi seçecektir. Üstelik Jean'ın içtiği şarap herhangi bir şarap değildir; altın yaldızlı bir Dijon şarabıdır. Bu seçim, Jean'ın yemeğini tıpkı servis yaptığı Kont gibi "keyifle" yemek istediğini gösterir. Bu noktada benzer bir yaklaşım Arif' in yemek yeme alışkanlığında da görülür. İnci kocasının yemek yeme alışkanlığından söz ederken onun hayata bakışına gönderme yapar; kocasının hiç kapanmayan ağzı aslında Arif'in varolan ekonomik sistem içindeki açgözlülüğünü ve firsatçıllığını imler.

\footnotetext{
${ }^{1}$ A.g.e. s., 288.
} 
İnci: Benim bildiğim ağız yemek zamanları açılır, yemek bitince kapanır, ta öteki yemeğe kadar. Ama sen durmadan bir şeyler atıştırırsın, durmadan öte beri yersin. ${ }^{l}$

Oyunun daha sonraki bölümlerinde Arif'in yeme alışkanlığının Servet Batmaz'ınkine benzerliği açığa çıkacaktır. Her iki karakter de hedefledikleri konumlardaki kişilerin yeme alışkanlıklarına sahip çıkarlar.

Oyunların erkek karakterlerinde belirgin olarak izi sürülen bir başka paralellik de hedeflerine giden yolda karşı tarafı aldatma yoluna gitmeleridir. Amaçlarına ulaşmak adına başvurdukları yollardan biri uydurma hikayelerle kendilerini karşılarındakilere farklı bir kimlik olarak tanıtmalarıdır. Matmazel Julie oyununda Jean, aralarında henüz bir ilişki yaşanmadan önce, Julie'yi uzun yıllardır sevdiği üzerine hikayeler anlatır.

Jean: (...) Gittim, sabunlu sıcak sularla yıkandım, en iyi giysilerimi giyindim, sırf sizi görmek için kiliseye gittim. Sizi orda gördüm ve ölmeye kararlı, eve döndüm. ${ }^{l}$

Jean, bu hikayesiyle ilgiye ihtiyacı olan Julie'nin gözünü boyar. Oyunun sonunda Julie'yi “içine doğduğu sınıfın dışına çıkmak için” kullandığını açıkça söyleyecektir. Tıpkı Yağmur Sıkıntısı oyununda, oyun öncesi zamanda Arif'in İnci'yi pahalı yerlere götürüp kendini zengin bir adam olarak tanıtıp gözünü boyaması gibi. Arif'in de kurulan düzenle bağını güçlendirmek adına İnci'yi yıllardır kullandığı, gözünün, İnci'nin sahip olduğu son değer olan eski evde olduğu açığa çıkacaktır. İki erkek karakterin ortak noktası, sınıf atlama umutlarını kadın karakterlerin varolan ya da varsayılan mal varlıklarına bağlamış olmalarıdır.

İki oyunun erkek karakterleri arasında görülen koşutlukları oyunların kadın karakterlerinde de saptamak mümkündür. Julie ve İnci, Jean ve Arif' in dünyalarının gerçeklerini anlayıp yorumlama ve onlarla çarpışma gücüne sahip değillerdir. Arif' in düzene sağladığı uyumun, rahatlığın tam tersine İnci uyumsuz ve dolayısıyla güçsüzdür. Aklıyla değil duygularıyla hareket eden İnci, kocasının ve çevresinin yozlaşmış ilişkileriyle tükenmiş, doğup büyüdüğü çevredeki mütevazı ve içten yılları özlemiş, Vedat ile olan ilişkisini de aynı duygularla o yıllara denklemiştir. Fakat sevginin ve duyguların Ariflerin dünyasında yeri yoktur. İnci'nin bu gerçeklerle karşılaştığında bunalıma girmesi kaçınılmaz olur. Zaman zaman zekasının getirdiği alaylı cümleleriyle kendi doğrularını dillendirir, geçici üstünlükler kazanır, ancak duygularıyla hareket edenler için bu zemin kaygandır. Ayağı kayacak olan elbette sımsıkı tutunmuş olan Arif olmayacak, zaaf kabul edilen duyguların sahibi İnci olacaktır. Çünkü Arif ve çevresindekilerin düzenini yıkmak için sevgiden yana olmak yeterli olmayacaktır. Oyunun hemen başında anlaşılan bunalımlı hali oyun geliştikçe açığa çıkar. İnci, kocasından çok farklı bulduğu Vedat'a aşık olmuş ve onunla bir yıllık bir ilişki yaşamıştır. Daha sonra aldatıldığını anlaması ile derin bir bunalıma girmiştir. Oyun boyunca Arif'in duymadığı bir erkek

\footnotetext{
${ }^{1}$ Strindberg, A.g.e. s., 268-269.
} 
sesiyle irkilir. Genç kadın, Vedat'la kurduğu düş dünyası ve kocasının gerçeklerinin dünyası arasına sıkışıp kalmıştır. Vedat'la yaşadığı aşk ile kocasıyla yaşadığı beraberlik iki uçta yer alır. O aşık olduğu adamın sesini bir iç ses gibi duyarken, kocası, sahip olmadığı arsaların seslerini duymaktadır:

Arif: Ne zamandan beri bilirim bu arsaları, öyle yüzüstü, bomboş dururlar. Oralara yolum düştükçe: "Arif, diye bağırırlar arkamdan, Arif, bize bak! Arif yahu, bizi böyle birakma!",2

Ancak İnci Vedat'ın kendisini aldattığına tanıklık edince derin bir bunalıma düşmüştür, bu durumu kocasına açıklayınca elindeki tek silahını yitirir. O ana kadar Vedat'ın ne kadar farklı ve özel bir adam olduğundan dem vuran İnci, kocasına karşı yücelttiği Vedat'ın kendisini Semra ile aldatmasını açığa vurunca, Arif bu silahı da eline geçirir. Arif de bir zamanlar karısını Semra ile aldattı̆̆ını söyler. İnci kocası karşısında tamamen güçsüz düşer. Aralarında galibi belli açık bir savaş devam ederken Arif tüm kozlarını oynamaya niyetlidir; anneden kalma evin satışını yeniden gündeme getirir. Daha önce evin satışına direnen İnci, kocasının onu Vedat'a rezil edeceği tehdidine boyun eğer. Oyunun başında önsemesi yapılan büyük son gerçekleşir. Sevgiden yana ince ve duygulu bir kadın da olsa, kocası ve çevresinin gerçekleriyle savaşmakta yetersiz kalır. Kocasının dünyası sevgiden doğan zaafları kabul etmediği gibi yetersizlikleri de hoş görmez. Yazarın tartışmaya açtı̆̆ 1 temel sorun da zaten burada yatar: Böyle temelsiz ve çarpık bir düzende haksızlar her zaman haklıları ezecek, kazanan taraf hakkını gücünden alan olacaktır. Gittikçe artan bunalımı, sıkışmışlığı, çaresizliğiyle Julie'nin Jean karşısında yenik düştüğü gibi, İnci de "köşe kapmaca" oyununda tüm köşelerini kaptırmıştır. Arif'in telkiniyle uyku ilacı alır.

Julie karakterine, Strindberg'in, özellikle gerçekçi oyunlarını bir senfoni gibi kurduğu düşüncesinden yola çıkarak baktığımızda, Julie'nin diğer oyun kişileri karşısındaki düşüş ve çıkışlarının melodinin iniş ve çıkışlarına denk düştüğü görülür. Julie'nin annesi dönemin kadın hareketlerinden etkilenmiştir. Seneca Falls Bildirileri, 19. yüzyıl kadın hakları hareketinin temel liberal doktrininin yararlı bir özeti olarak hizmet etmektedir. Seneca Falls'a giden yolun kuramsal çerçevesinin Aydınlanma geleneğinde yer alan güçlü birçok feminist düşünürün kuramları çizmiştir. Aydınlanmacı Liberal Feministler aşağıdaki temel düşünceleri paylaşmaktadırlar; 1. Akla inanç. Wollstonecraft gibi bazı düşünürlere göre, akıl ve Tanrı neredeyse eş anlamlıdır. Birey, aklı içinde tanrısal bir kıvılcım barındırır; bu kişinin vicdanıdır. 2. Kadının ve erkeğin ruhları ile akılcı yeteneklerinin aynı olduğu inancı. 3. Toplumsal değişime ve toplumun dönüşümüne etki etmenin en iyi yolunun eğitim, özellikle eleştirel düşünebilmek için eğitim olduğuna inanç. 4. Bireyin diğer bireylerden ayrı olarak gerçeği arayan, akılcı ve bağımsız bir aktör olarak hareket eden ve haysiyeti

\footnotetext{
${ }^{1}$ Strindberg. Ön.ver.,s., 111.

${ }^{2}$ Rifat, Ön.ver., s., 272-273.
} 
bağımsızlığına bağlı olan yalnız bir varlık olduğu görüşü. Ancak anne, yaptı̆̆ı evlilikle, kendisini evini yakmaya kadar götüren bir bunalımın içinde bulur. Julie'nin annesi evliliğe karşıyken bir kontun "karısı" olmuş, çocuk sahibi olma fikrinde değilken Matmazel Julie’yi dünyaya getirmiştir. İnandığı değerlerin tam tersi bir yaşam sürdüren kadının bu duruma son vermek adına giriştiği işlerin tümü felaketle sonuçlanmıştır. Çünkü anne yukarıda sözü edilen kadın hareketi ilkelerini hiçe saymış, yalnızca kadınların erkeklerden aşağıda kalmamaları gereğinden hareket etmiş, bunu sağlayacak diğer çevresel etmenleri göz önüne almamıştır. Kadınların erkek işlerini yapabilecekleri ile ilgili savı ev ahalisini dile düşürürken kızını kimlik bunalımına ve aidiyet duygusundan yoksunluğa mahkum etmiştir. Yaşadığı ikilemlerin sonucu hastalanmış, Kont, olup bitene dur demek isteyince evi yakmıştır. Ayrıca bir önemli nokta da Matmazel Julie'nin annesinin hayatında bir " yasak aşk” olmasıdır. Bu yasak aşk yalnızca bir gönül ilişkisi olmayıp aynı zamanda maddi bir ilişkiyi de içinde barındırır. Elindeki birikmiş parayı sevgilisine "yatıran” kadın, böylece kocasını, yanan evin onarımı için -aslında kendisine ait olan parayı- karısının aşığından borç almak durumunda bırakmıştır. Julie, çocukluğunu, annesinin, bir kadın olarak, babası üzerinde kurmak istediği üstünlük savaşı ve sonuçlarıyla geçirmiştir. Julie'ye ilkelerden uzak feminist anlayıştan kalan, erkeklerden tiksinmek ve annesine, hiçbir erkeğin kölesi olmayacağına dair verdiği sözdür. Gerçekçi ve Natüralist kuram anlayışına göre kişinin çevresini saran etmenler yazgısal bir kesinlik içindedir. Strindberg'in Julie'si de kalıtıma ve çevresine yazgılıdır. Farkındalıktan yoksundur ve aidiyet duygusu gelişmemiştir. Jean, hedefine ulaşmak adına Julie'nin bu zaaflarından faydalanır. Tıpkı Arif'in İnci'yle oynadı̆̆ı "köşe kapmaca"da yaptığı gibi, Jean da kendi çıkarları doğrultusunda tüm köşeleri kapar.

Julie geldiği noktada kişiliğinden "kabahat" olarak söz eder. Ancak bu kabahatin kime ait olduğu sorusunun cevabını bulamaz. Cevap onun çevresine ve koşullara olan yazgısında yatar. Kendi ağzından da duyduğumuz gibi anneden kalıtımla geçenler, anne ve baba tarafından öngörülen çevresel koşulların birbiriyle sürekli çatışma halinde olması Julie'nin sahibini aradığı "kabahat"in kendisidir. Matmazel Julie bu kabahati ancak kendisine öngörülen koşulların ikisinin de dışına çıktığında fark eder. Kendisine ait hiçbir şeyi olmadığını söyleyen Julie, ilk kez kendisine ait bir suç işleyecektir. Jean'la beraber olarak annesine erkeklere teslim olmayacağı konusundaki sözünü çiğnerken, bir yandan da babasının ona sağladığı toplumsal konumu zedelemiş olur. Julie kendi kişiliğinin oluşumundaki kabahatleri üstlenmezken, üstlendiği suçun da altında ezilecektir. Kendisini intihara götürecek olan süreç bu ezikliği barındıracakken aynı zamanda Julie'nin eylemi onurlu olacaktır. Çünkü Kristin gibi işlediği günahları İsa'nın üzerine yıkmak yerine ilk kez kendisine ait olan bir şey için bedel ödeyecektir. Şimdiye kadar ödediği hiçbir bedel ona suçu sahiplenme olanağı vermemiştir; çünkü onlar babasının ve annesinin kabahatleridir. Bütün bu sorgulama ve sona yaklaşmış olmak Julie'nin olduğu kadar Jean'ın da gücünü tüketmiştir. Jean'ın oyunu boşa çıkmış ve artık efendi karşısında çaresiz kalmıştır. Bundan sonra oyun zamanı boyunca olan her şeyin örtbas edilmesinden 
başka yapılacak bir şey kalmamıştır. Julie "git"melidir. Yazarın oyuna yazdığı son cümleyle Julie kapıdan dimdik çıkar. Bu eylemle Julie, Jean'ın “ilk dala ulaşma” rüyasını da yanında götürerek "ambara doğru" gider.

Aşağıda karşıtlıkları bir tablo halinde sıralanmış İnci-Julie ve Arif-Jean karakterlerine bakıldığında, bu karşıtlıklardan ancak bir kazanan bir kaybedenle çıkılacağı, dengelenmesi imkansız karşıtlıkların galip ve mağlup yaratacağı görülecektir:

\section{INCÍ-JULIE ARİF-JEAN}

$\begin{array}{ll}\text { Kadın } & \text { Erkek } \\ \text { Bitkin } & \text { Enerjik }\end{array}$

Düş dünyasında Gerçeklere bağlı

İnce Kaba

Duygulu Hoyrat

Güçsüz Güçlü

Ezilen Ezen

\section{Kaybeden Kazanan}

Yağmur Sıkıntısı oyununun sahnede hiç görmediğimiz Semra karakterine baktığımızda, İnci karakterinin tam tersine Arif ve Servet Batmaz'ın dünyalarıyla barışık bir kadın tipi görürüz. Gösterişli, becerikli, cilveli bir duldur. İnci’yle karşıtlıkları bu kadarla kalmaz, İnci zaaf kabul edilen duygularıyla örselenmiş karakterken, Semra böyle bir zaafa uzaktır. Tıpkı Matmazel Julie oyunun Kristin'i gibi. Jean ile arasında geçen evlilik dışı ilişki, bakkaldan yapılan alışverişlerden komisyon alması, haksız elde ettiği parayı biriktirmesi aslında kendisinin de çok iyi bildiği Hıristiyan öğretisine tamamen ters düşer. Kristin'in aslında günahlarla dolu yaşamını sürdürürken bulduğu çıkış her pazar kiliseye gidip, vaaz dinlemek, günah çıkarmak ve İsa ile günahlarını paylaşarak arınmaktır. Bu anlamda Kristin seçkisiyle yaşama dair bir denge kurmuş, attığı her yanlış adım, işlediği her günah bu denge içinde onu yaşama sağlam tutunmuş bir kişi haline getirmiştir. Bu bağlamda, Darwin'in Evrim Teorisi'nde değinildiği gibi “doğada ortamına en iyi uyabilenin yaşama hakkını elde ettiği” görüşü Kristin gibi Jean, Arif, Semra karakterlerinde de karşılı̆̆ını bulur. 
Oyunlarda sözü edilen ve oyun boyunca sahnede hiç görmeyeceğimiz iki oyun kişisi daha vardır: Servet Batmaz ve Kont. Bu iki oyun kişisi sahnede hiç yer almamalarına rağmen yapısal olarak oyun kişileriyle önemli katlanmalara sahiplerdir. Servet Batmaz, yazar tarafindan özenle konulmuş bir isme sahip, Arif' in hayranlıkla öykündüğü bir karakterdir. Sahip olduğu serveti batırmamayı başarmış, piyasa düzeninin rüzgarında iflaslardan büyük sermayeler yaratmayı bilmiş bir iş adamıdır. Oysa Arif para karşısında henüz Servet Batmaz kadar sakin değildir, henüz o aşamalara gelememiş tam bir "işadamı" olamamıştır:

Arif: (...) Servet Batmaz hiçbir zaman tam bir işadamı gözüyle bakmaz bana. Neden? (Heyecanlı) Çünkü para şakır şakır oluklardan akarken ben çılgına dönerim. Çırılçıplak soyunup yıkanmak isterim o yağmurun, o selin altında. Para alsın götürsün beni! ${ }^{l}$

Arif' in Servet Batmaz'a öykünmesi gibi Matmazel Julie oyununda Jean, ait olma savaşı verdiği sınıfın bir üyesi olan Kont'a öykünür. Kont'un sahip olduğu erk, uşağına boğazını kesmesini emrettiği takdirde bunu yaptıracak kadar güçlüdür. Jean böylesi bir gücü özler:

Jean: Bugün bir uşağım, gelecek yıl mülk sahibi, derken on y1l içinde koca bir servet yığarım, sonra ver elini Romanya, takıp takıştıır, belki de bir kont olur çıkarım. ${ }^{2}$

Sözü edilen oyunların ortak mekanı mutfaktır. Matmazel Julie oyunundaki üç kapının da geniş mutfağa açılıyor olması aksiyon açısından işlevseldir. Oyun boyunca giriş çıkışlar, yalnız kalışlar, sıkışmışıklar bu üç kapıyla çevrili oyun mekanında gerçekleşir. Konağın çalışanlarından Jean ve Kristin için "mutfak" aynı zamanda bir yaşam alanıdır. İşini bitirip, önlüğünü bir tarafa bırakan Kristin, saçını yine mutfakta maşalar, zaman zaman orada uyuklar. Jean, Kont'un kilerinden "aşırdığı”" şarapları buraya saklar, burada rahatça üstünü değiştirir. Matmazel Julie için ise "mutfak" bir yaşam alanı değildir; kendi sınıfsal konumunu gözetmeksizin onların yaşam alanına girer ve ait olmadığı bir mekânda ait olduğu sınıfı yadsır biçimde davranır. Yazarın camlı kapıların ardından görünmesini istediği "Cupido'lu Çeşme” oyun için önemli bir dramatik göstergedir. Yazar, aşkı imleyen ve aynı zamanda "arzu"1 anlamına gelen bu göstergeyi oyun boyunca görünür kılmıştır. Bu görünür kı1ış, hem oyunun izleğiyle örtüşür, hem de izleyiciyi perde açılır açılmaz karşı karşıya kaldığ 1 Eros/Cupido heykeliyle oyundaki ilişkiye hazırlar. Yağmur Sıkıntısı oyunda ise yazar mutfağı, oyununun gelişiminde ciddi bir sıkışmışlık duygusu yaratacak biçimde düşünmüştür. Tarif edilen dekor modern bir apartman dairesinde bir mutfağa aittir, ancak bu modern apartman dairesinin sakinleri kahvaltılarını mutfakta ederler. Bu, oyun kişilerinin sosyal statülerini ele veren bir ipucu olarak oyun başlamadan kendini ele verecektir. Ayrıca İnci’nin şık giysileri içindeki bitkinliği ve Arif’in yere

\footnotetext{
${ }^{1}$ A.g.e., s., 289.

${ }^{2}$, Strindberg. Ön.ver, s., 116.
} 
sürünen sabahlığı kendi içlerinde karşıtlık oluşturan göstergelerdir. Oyunlarda mutfakta bulunan ve aksiyon açısından da değer taşıyan bir dramatik nesne olarak telefondan söz edilebilir.

Her iki oyunun da sonunda telefonla gelen haber İnci'yi ve Julie'yi kaçınılmaz sonlarıyla baş başa bırakırken Arif'i ve Jean'ı hayatlarının eski gereklerine döndürür. Julie intihara yürürken, Jean, yeniden Kont'un çizmelerini ve kahvesini yetiştirmekle görevli uşak olur. Arif, yaptı̆̆ kanunsuz iş sebebiyle arandığı için “ortadan kaybolmaya” hazırlanırken İnci’yi uyku ilaçlarıyla baş başa bırakır.

Özetleyecek olursak, farklı dönemlerde, farklı tiyatro anlayışlarının temsilcileri olan yazarlar tarafından kaleme alınmış olan söz konusu oyunlar, iki farklı toplum insanının yaşadığı değer değişimi ve sonuçlarını işler. Oktay Rifat ve Auguste Strindberg'in aynı izlek üzerine kurdukları oyunlarında işleyiş biçimlerindeki paralellikler ve farklılıklar ait oldukları tiyatro anlayışlarının ipuçlarını taşımaktadır.

\section{KAYNAKÇA}

Dent, Antony. International Modern Plays. Çeviren: C.D. Locock. Londra: Dent Dutton, 1967. Donavan, Josephine. Feminist Teori. Çeviren: Aksu Bora. İstanbul: İletişim Yayınları, 1997. Erhat, Azra. Mitoloji Sözlüğ̈̈. İstanbul: Remzi Kitabevi, 1983.

Rifat, Oktay. Toplu Oyunları. İstanbul: Adam Yayınları,1988

Strindberg, August. Strindberg Seçilmiş Oyunlar 1. Çeviren: Aziz Çalışlar, Turan Oflazoğlu, Afif Obay. İstanbul: Adam Yayınları, 1982.

Tanilli, Server Uygarlık Tarihi. İstanbul: Cem Yayınevi, 1992.

Tünay, Muharrem. Siyasal Tarih. Ankara: İmge yayınevi, 1995.

\footnotetext{
${ }^{1}$ Azra, Erhat. Mitoloji Sözlüğ̈̈̈. (İstanbul: Remzi Kitabevi: 1983), s.,183.
} 